\title{
Dynamics of the Foliar Pigments Content in some Tomato Cultivars from East Romania under Salt Stress
}

\author{
Mihaela BOLOGA (COVAȘĂ) $)^{1 *}$, Carmen Doina JITĂREANU ${ }^{1}$, Cristina SLABU ${ }^{1}$, Alina Elena MARTA ${ }^{1}$ \\ ${ }^{1}$ Department of Biological Sciences, University of Agricultural Sciences and Veterinary Medicine of Iasi, \\ Mihail Sadoveanu Alley, no. 3, 700490 Iasi, România; \\ * corresponding author: miha_bologa@yahoo.com
}

Bulletin USAMV series Agriculture 72(1)/2015

Print ISSN 1843-5246; Electronic ISSN 1843-5386

DOI 10.15835/buasvmcn-agr: 10525

\begin{abstract}
The biological material was represented by ten local tomatoes populations collected from areas with saline soils from Moldavia region and compared with commercial type salt-tolerant tomato Determination of photosynthetic pigments of leaves was done by the spectrophotometric method. For determination of photosynthetic pigments of leaves we used a UV spectrophotometer type - 1800. The content of chlorophyll pigments was assessed by light absorption ability of the acetone extract of pigments (1\%) in the visible spectrum (400-700 nm). Tomato genotypes in the study were subjected to salt stress for a period of 30 days is constantly wetted with saline solution to a concentration of $100 \mathrm{mM}$ and $200 \mathrm{mM}$. The pigment content was analyzed at 15 days and 30 days after the saline treatment. After 15 days when the tomato genotypes was subjected to constant stress salt the content of chlorophyll $a_{662-663}$ chlorophyll $a_{431-432}$, chlorophyll $b_{453-454}$ and chlorophyll $b_{616-617}$ showed higher values compared with analyzes performed after 30 days. Analyzed the results based on biphasic model of growth response under salt stress proposed by Munns (1993), and found that tomatoes reacted similarly. The transition from phase I (osmotic stress) to phase II (ions toxicity), is done by salt stress intensity, but mostly by cultivated genotype.
\end{abstract}

Keywords: Lycopersicon esculentum, photosynthetic pigments, salt stress.

\section{INTRODUCTION}

The impact of excess soil salinity on crop productivity is sometimes disastrous which results, in the identification and design of new genotypes of plants tolerant to osmotic stress conditions. One of the main reasons is that the basic mechanisms of tolerance to the stress are not fully understood.

Soil salinity is an important abiotic stress factor seriously affecting plant productivity and survival. Growth and development of glycophytes are negatively affected but halophytes tolerate high salt concentrations Doganlar Z.B. et al., (2010).

Currently there are no indicators of salinity tolerance in plants that contribute to the improvement of crops (Asharaf, 2004). Photosynthesis and growt of many plants are inhibited under $\mathrm{NaCl}$ salinity. On tomato resistance to salinity Pessarakli (2011) shows a moderate sensitivity ( $\left.\mathrm{T}=2.5 \mathrm{dS} \mathrm{m}^{-1} \mathrm{~m}^{-1}, \mathrm{~S}=9.9 \%\right)$ and the cherry tomatoes (L.lycopersicum var.cerasiforme), also a moderate sensitivity $\left(\mathrm{T}=1.7 \mathrm{dS} \mathrm{m}^{-1} \mathrm{~m}^{-1}\right.$, $\mathrm{S}=8.1 \%)$.

\section{AIMS AND OBJECTIVES}

We studied the effects of salt stress on the chlorophyll pigments content in some tomato cultivars, by the spectrophotometric method.

\section{MATERIALS AND METHODS}

The research was conducted undergreenhouse condition and the analysis in the Laboratory of Plant Physiology, Faculty of Agriculture, from USAMV Iași.

The biological material was represented by local tomatoes populations collected from areas with saline soils from Moldavia region and 
compared with commercial type salt-tolerant tomato (Ursula ${ }_{F 1}$ ) from Israel. The bifactorial experience was conducted in a pots experiment in randomized blocks with four repetitions. Ten tomato genotypes (Moșna 2, Șcheia, Dorohoi ${ }^{\prime}$ Dorohoi , Dorohoi ${ }_{6}$ Copalău ${ }_{2}$, Copalău ${ }_{3}$, Copalău ${ }_{4}$ Copalău ${ }_{5}$, Moșna $_{3}$ ) studied were subjected to salt stress for a period of 30 days is constantly wetted with saline solution to a concentration of $100 \mathrm{mM}$ and $200 \mathrm{mM}$. For determination of photosynthetic pigments ofleaves we used aUV spectrophotometer type - 1800. The content of chlorophyll pigments was assessed by light absorption ability of the acetone extract of pigments (1\%) in the visible spectrum (400-700 $\mathrm{nm})$.

\section{RESULTS AND DISCUSSION}

After 15 days the application of saline treatments the experimental results showed value between 1.00 and 1.83 u.a for chlorophyll a ${ }_{662-663}$ $n m$ absorbance, the values being the higher Ursula ${ }_{F 1}$ variety $(0,46 \mathrm{u} . \mathrm{a})$, resistant to excess $\mathrm{NaCl}$. The exposure to $100 \mathrm{mM} \mathrm{NaCl}$ caused an increase of absorbance values in all 11 genotypes subjected to salt stress compared to the control which is between 1.20 and 1.83 u.a, and compared to salttolerant type Ursula $_{F 1}$ (1.73 u.a.) $100 \mathrm{mM}$ a single cultivar (Copalău ${ }_{5}$ ) showed higher values, namely 1.83 u.a. The other 9 cultivars had lower values between 1.20 and 1.53 u.a. The exposure to 200 mM NaCl caused an increase of absorbance values at 8 genotypes subjected to salt stress compared to the control which is between 1.30 and 2.23 u.a, and compared to salt-tolerant type Ursula (1.30 u.a.) 200 mM, 9 genotypes showed higher values between 1.40 and 2.23 u.a. That shows the variations of the first phase in the specific salt stress, osmotic stress phase, depending on the genotype and on the concentration of the salt solution This phase is reflected by the high pigments content, when is adversely affected only cell elongation but not chlorophyll biosynthesis, the chloroplasts accumulate in a lower volume. In case of chlorophyll $a_{431-432}$, chlorophyll $b_{453-454}$ and chlorophyll $b_{616-617}$ the plants reaction is similar.

After 30 days the application of saline treatments the experimental results showed value between 0.66 and 4.00 u.a for chlorophyll a ${ }_{662}$ ${ }_{663} \mathrm{~nm}$ absorbance. Compared to Ursula ${ }_{F 1}$ variety $(0,93$ u.a), six of the ten genotypes studied showed higher values between 1.10 and 4.00 u.a and the other four genotypes lower values between 0.66 and $0.80 \mathrm{u}$. The exposure to $100 \mathrm{mM} \mathrm{NaCl}$ caused an decrease of absorbance at 2 of the 11 genotypes with values between 0.66 and 0.86 u.a. compared to the control, and the other genotypes values was higher between 1.20 and 3.00 u.a. Compared to Ursula $_{F 1}$ variety (3.00 u.a.) $100 \mathrm{mM}$ all genotypes show lower values between 0.66 and 2.00 u.a. The exposure to $200 \mathrm{mM} \mathrm{NaCl}$ caused a decrease in absorbance at 5 genotypes compared to the control, this values between 0.56 and 1.36 u.a. This shows they were in stage II of the stress and the other values were higher between 1.53 and 1.90 u.a. of which are still in the first phase of stress. Compared to Ursula ${ }_{F 1}$ variety (1.46 u.a.) $200 \mathrm{mM}$ 9 of the 10 show lower values between $0.56-1.53$ u.a. In case of chlorophyll $a_{431-432}$, chlorophyll $b$ ${ }_{453-454}$ and chlorophyll $b_{616-617}$ the plants reaction is similar.

Analyzed the results based on biphasic model of growth response under salt stress proposed by Munns (1993), we found that studied tomatoes reacted similarly. The transition from phase I (osmotic stress) to phase II (ions toxicity), is done by salt stress intensity, but mostly by cultivated genotype.

\section{CONCLUSION}

After 15 days when the tomato genotypes was subjected to constant stress salt the content of chlorophyll $a_{662-663}$ chlorophyll $a_{431-432}$, chlorophyll $b_{453-454}$ and chlorophyll $b_{616-617}$ showed higher values compared with analyzes performed after 30 days. The transition from phase I (osmotic stress) to phase II (ions toxicity), is done by salt stress intensity, but mostly by cultivated genotype.

\section{REFERENCES}

1. Asharaf M., Harris P.J.C (2004). Potential biochimical indicators of salinity tollerance in plants. Plant Science, 166:3-16.

2. Doganlar Z.B., Demir K., Gul I. (2010). Effects of salt stress on pigment and total soluble protein contents of three different tomato cultivars. African Journal of Agricultural Research Vol. 5(15): 2056-2065.

3. Munns R., (1993). Physiological processes limiting plant growth in saline soils: some dogmas and hypotheses. Plant Cell and Environment 16:15-24.

4. Pessarakli M. (2010).Handbook of Plant and crop stress. Third Edition, CRC Press. 